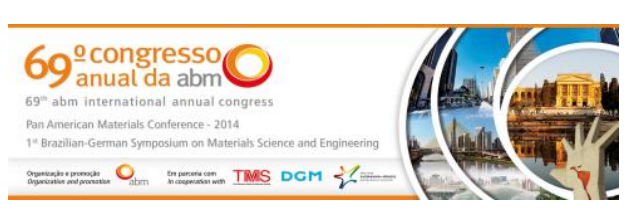

Tema: Metalurgia física e comportamento de materiais em temperaturas elevadas

\title{
EVOLUÇÃO MICROESTRUTURAL, TEXTURA E COMPORTAMENTO MECÂNICO DO AÇO TRIP/TWIP 17Mn- 0,06C APÓS LAMINAÇÃO A QUENTE, A FRIO E RECOZIMENTO*
}

\section{Resumo}

Sara Silva Ferreira de Dafé 1 Alessandra Cunha Ferreira² Isabela Viegas Aguiar ${ }^{3}$ Dagoberto Brandão Santos ${ }^{4}$ Diana Maria Péres Escobar ${ }^{5}$

Os aços com um alto teor de $\mathrm{Mn}(15-30 \%)$ e os elementos de liga, Si e Al, apresentam plasticidade excepcional devido à geração de maclas de deformação (efeito TWIP) ou múltiplas transformações martensíticas (efeito TRIP). Este trabalho avaliou a evolução microestrutural, a formação da textura e sua influência sobre o comportamento mecânico de um aço contendo $17 \% \mathrm{Mn}-0,06 \% \mathrm{C}$ laminado a frio com reduções de $45 \%$ e $90 \%$, e recozimentos a $700^{\circ} \mathrm{C}$ durante tempos diferentes. A microestrutura foi analisada por microscopia óptica e eletrônica de varredura, EBSD e difração de raios $X$. A redução um frio favorece a formação da martensita $\alpha$ '. No aço recozido estão presentes as fases martensita $\alpha^{\prime}$ e $\varepsilon$ e austenita. $O$ limite de escoamento e de resistência à tração alcançaram 750 e $950 \mathrm{MPa}$, respectivamente, com o alongamento total de $45 \%$, confirmando sua alta capacidade de encruamento. A reversão da martensita para austenita ocorre simultaneamente com a recristalização desta.

Palavras-chave: Aço alto manganês; Aço TRIP; Aço TWIP; Martensita.

\section{MICROSTRUCTURAL EVOLUTION, TEXTURE AND MECHANICAL BEHAVIOR OF TRIP Abstract STEEL 17Mn TWIP-0.06c AFTER HOT ROLLING, ANNEALING AND COLD}

Steels containing high contents of $\mathrm{Mn}, \mathrm{Si}$ and $\mathrm{Al}$ have great plasticity when deformed due to TWIP or TRIP effects. This work evaluated the microstructural evolution, texture formation and its influence on the mechanical behavior of a steel containing $17 \% \mathrm{Mn}$ and $0.06 \% \mathrm{C}$ after cold rolling to $45 \%$ and $90 \%$ of reduction, and annealing at $700^{\circ} \mathrm{C}$ for different times. The microstructures were analyzed by optical and scanning electron microscopy. Volume fraction of the phases $\gamma, \varepsilon$ and $\alpha^{\prime}$ martensites were measured by $\mathrm{X}$-ray diffraction and EBSD technique. It was found that cold reduction increases the $\alpha$ martensite volume fraction. The relative phase amounts showed that the sample annealed for the longest time, $1000 \mathrm{~s}$, still presents $\varepsilon$ and $\alpha^{\prime}$ martensite. The yield and tensile strength for annealing condition reach values close to 750 and $950 \mathrm{MPa}$, respectively, with total elongation of $45 \%$, confirm the high work hardening rate of the analyzed steel.

Keywords: Manganese steel; Hot rolling; Cold rolling; Recrystallization; TRIP steel.

1 Doutora, Programa de Pós-Graduação em Engenharia Metalúrgica e de Minas, UFMG, Belo Horizonte, MG, Brasil.

2 Aluna de Graduação, Eng. Metalúrgica, Depto. de Eng. Metalúrgica e de Materiais, Escola de Engenharia, UFMG, Belo Horizonte, MG, Brasil.

3 Professor Associado, Departamento de Engenharia Metalúrgica e de Materiais, Escola de Engenharia, UFMG, Belo Horizonte, MG, Brasil.

4 Pós-Doutoranda, CAPES, Programa de Pós-Graduação em Engenharia Metalúrgica e de Minas (PPGEM), UFMG, Belo Horizonte, MG, Brasil.

5 Universidade Federal de Minas Gerais.

Contribuição técnica ao 69ํㅡㄹ Congresso Anual da ABM - Internacional e ao 14ํㅡㄹ ENEMET - Encontro Nacional de Estudantes de Engenharia Metalúrgica, de Materiais e de Minas, 21 a 25 de julho de 2014, São Paulo, SP, Brasil. 


\section{INTRODUÇÃO}

Os aços contendo teores elevados de $\mathrm{Mn}$, Si e Al, exibem plasticidade elevada quando submetidos à deformação devido à maclação mecânica, conhecido como efeito TWIP (Twinning Induced Plasticity), ou à transformação martensítica, denominado efeito TRIP (Transformation Induced Plasticity) [1-3]. Os aços TWIP/TRIP são uma alternativa promissora para atender a demanda na construção de peças automotivas que exigem um material com alta resistência, alta conformabilidade, boa tenacidade e menor densidade. A absorção de choque desses aços é o dobro da verificada em aços de alta resistência convencionais usados para estampagem profunda [1,4-6]. Estas características levaram, principalmente, as indústrias automotivas a se interessarem pela aplicação desse produto, visando a economia de combustível, a segurança dos passageiros, a redução de peso e diminuição da emissão de gases poluentes no meio ambiente [4-6].

Uma das principais variáveis que determina o mecanismo de deformação plástica nesses aços é a energia de falha de empilhamento, EFE, [7-10].

Segundo Dumay et al. [11], para valores de EFE superiores a $18 \mathrm{~mJ} / \mathrm{m}^{2}$ o efeito TWIP prevalece, enquanto que para valores inferiores, o efeito TRIP é predominante, enquanto a formação de martensitas dos tipos $\varepsilon$ e $\alpha$ ' acontece para EFE inferior a 12 $\mathrm{mJ} / \mathrm{m}^{2}$. A morfologia e fração volumétrica da martensita $\alpha$ 'é fortemente influenciada pela presença da martensita $\varepsilon$, uma vez que a martensita $\alpha$ ' é formada a partir da martensita $\varepsilon$, a qual nucleia nas falhas de empilhamento da estrutura austenítica [12]. Em contrapartida, a EFE depende fortemente da composição química, da temperatura de deformação e do tamanho de grão da austenita. Sabe-se que a EFE em ligas de Fe$\mathrm{Mn}-\mathrm{C}$ é relativamente baixa, e para ligas com o teor de $\mathrm{Mn}$ entre $15 \%$ e $25 \%$, os efeitos TRIP e TWIP coexistem [3]. Entretanto, a adição de elementos de liga tais como o Al e $\mathrm{Ni}$ elevam a EFE e tendem a inibir a transformação martensítica $\left(\gamma_{\mathrm{cfc}} \rightarrow \varepsilon_{\mathrm{hc}} \rightarrow \alpha^{\prime}{ }_{\mathrm{ccc}}\right.$ ), enquanto que o Si diminui a EFE, favorecendo a formação da martensita [6,11-13].

Como mencionado, uma outra variável que controla a estabilidade da austenita é o seu tamanho de grão, uma vez que a formação de martensita é diminuída em função de uma elevada área superficial por unidade de volume de contornos de grão [14]. Por seu turno, o aumento do tamanho de grão austenítico favorece o crescimento da martensita [11]. A microestrutura austenítica mantém certa estabilidade durante todo o processo de deformação plástica [15], à medida que a deformação prossegue, maclas de deformação são formadas no interior dos grãos e também arranjos de discordâncias planares. Essas maclas agem semelhantemente aos contornos dos grãos, atuando como barreiras ao deslizamento das discordâncias, refinando a microestrutura e, assim, é possível alcançar, apesar da alta resistência, altos valores de alongamento e elevada capacidade de absorção de energia [3,4,6].

A elevada taxa de encruamento do aço alto Mn durante a deformação contribui consideravelmente para sua rápida recristalização no recozimento em função da energia armazenada. A desorientação entre os grãos ou regiões da microestrutura e a formação de subestrutura devido à essa deformação aceleram os processos de restauração [16-18]. A maioria dos aços austeníticos, tais como os aços inoxidáveis e alto manganês, têm de baixa a moderada energia de falha de empilhamento, entretanto tendem a formar falhas de empilhamento e maclas de recozimento. Estes diferentes defeitos na rede cristalina exercem uma forte influência na formação da textura durante a laminação a frio e no recozimento posterior [19-21].

Contribuição técnica ao $69^{\circ}$ Congresso Anual da ABM - Internacional e ao $14^{\circ}$ ENEMET - Encontro Nacional de Estudantes de Engenharia Metalúrgica, de Materiais e de Minas, 21 a 25 de julho de 2014, São Paulo, SP, Brasil. 


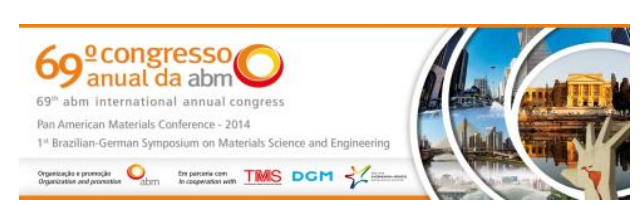

O presente trabalho teve como finalidade avaliar o efeito da laminação a frio na formação microestrutural e na textura, bem como no comportamento mecânico do aço TRIP/TWIP 17\%Mn e 0,06\%C recozido a $700^{\circ} \mathrm{C}$ durante 100, 300 e $1000 \mathrm{~s}$ após laminação a frio com $45 \%$ e $90 \%$ de redução. Durante as etapas de processamento termomecânico acontece a formação de martensita $\varepsilon$, que em seguida se transforma em $\alpha$ ', alterando significativamente o comportamento mecânico da liga. A composição química aqui utilizada, isto é, baixo teor de carbono, é muito pouco relatada na literatura. No que diz respeito à textura, somente um trabalho foi encontrado [21]. Contudo, os resultados aqui alcançados até o momento são bastante promissores para aplicação industrial do aço em questão.

\section{MATERIAIS E MÉTODOS}

A composição do aço usado é listada na Tabela 1. O aço foi fudido em forma de bloco Keel, ASTM A370, ao ar natural em um forno de indução (Power Trak 250-10 R Inductotherm $\AA$ ). $\mathrm{O}$ vazamento e fundição ocorreram a $1558^{\circ} \mathrm{C}$ e $1510^{\circ} \mathrm{C}$, respectivamente. Placas foram removidas dos blocos Keel, figura 1, austenitizadas a $1100^{\circ} \mathrm{C}$ durante $2 \mathrm{~h}$ e depois resfriadas ao ar para homogeneizar a sua microestrutura e a composição química. Após a homogeneização, as amostras foram cortadas para laminação a quente, que aconteceu a $1070^{\circ} \mathrm{C}$, com quatro passes de igual redução, levando a uma redução total de $50 \%$, com espessura final de $12,0 \mathrm{~mm}$.

Tabela 1. Composição química (\%peso)

\begin{tabular}{cccccc}
\hline Elemento & $\mathrm{Mn}$ & $\mathrm{Al}$ & $\mathrm{Si}$ & $\mathrm{Ni}$ & $\mathrm{C}$ \\
\hline Teor & 17,0 & 3,0 & 2,0 & 1,0 & 0,06 \\
\hline
\end{tabular}

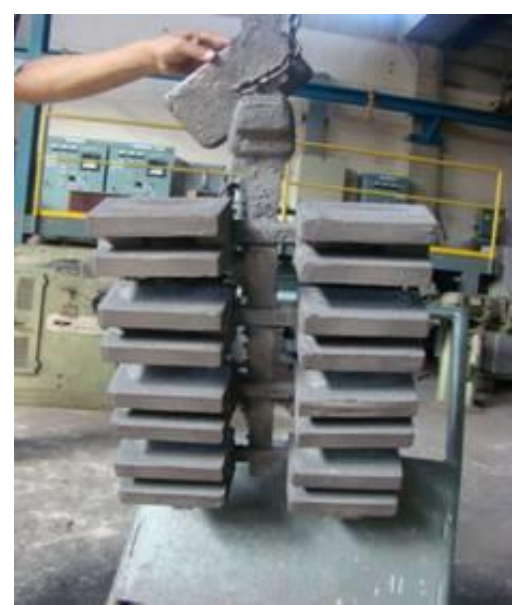

Figura 1. Blocos Keel logo após a remoção do molde.

Para laminação a frio, usinou-se o material até o desaparecimento total da carepa e, a partir daí, promoveu-se uma sequência de 7 passes de forma a obter uma redução total de $45 \%$, atingindo-se $7 \mathrm{~mm}$ de espessura final. Outra sequência de 32 passes foi aplicada para se obter $90 \%$ de redução com espessura final de $1,2 \mathrm{~mm}$. O aço foi recozido na temperatura de $700^{\circ} \mathrm{C}$, em tempos de $100,300,1000 \mathrm{~s}$ e resfriado em ar natural.

Após o recozimento, as amostras foram embutidas a quente e preparadas de maneira convencional até o polimento com pasta de diamante de $0,25 \mu \mathrm{m}$. Posteriormente, foi realizado o polimento em uma politriz automática com uma mistura de sílica coloidal e

Contribuição técnica ao 69 Congresso Anual da ABM - Internacional e ao 14ํㅡㄹ ENET - Encontro Nacional de Estudantes de Engenharia Metalúrgica, de Materiais e de Minas, 21 a 25 de julho de 2014, São Paulo, SP, Brasil. 


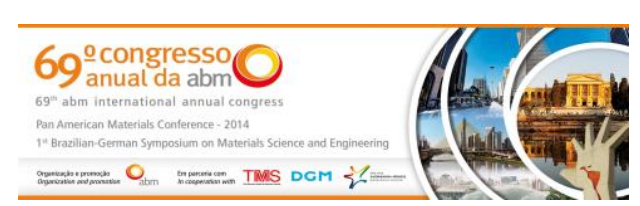

lubrificante metalográfico durante 60 min. A seção examinada corresponde à espessura, plano DL-DN. A microestrutura das amostras foi caracterizada por microscopia óptica e eletrônica de varredura, após ataque químico com reativo de Villela. A difratometria de raios $X$ foi realizada à temperatura ambiente em um difratômetro Pan Analytical Empyrian, usando um tubo de cobre $(\lambda=0,1540 \mathrm{~nm})$ e um monocromador de Ni. A condições operacionais foram $45 \mathrm{~mA}$ e $40 \mathrm{kV}$ com $2 \theta$ variando de 10 a $110^{\circ}$ em varredura contínua com $0,02^{\circ}$ de intervalo entre cada aquisição e $1 \mathrm{~s}$ por passe. A quantificação das fases austenita, martensitas $\varepsilon$ e $\alpha^{\prime}$ foi realizada pelo método de integração da área abaixo dos principais picos de difração. A integração das intensidades foi feita com o auxílio do software Origin ${ }^{\mathrm{TM}}$, seguindo a metodologia descrita no trabalho de Dafé et al. [22,23]. A difração por elétrons retroespalhados (EBSD) foi realizada para quantificar a microestrutura e obtenção da microtextura, utilizando um passe de 0,2 $\mu \mathrm{m}$. Também foram realizados ensaios de tração à temperatura ambiente a uma taxa de deformação de $10^{-3} \mathrm{~s}^{-1}$ e medidas de microdureza Vickers com carga de 2,9 N (300 g), para verificar a variação da fração recristalizada com o tempo de recozimento a partir do comportamento mecânico.

\section{RESULTADOS E DISCUSSÃO}

\subsection{Caracterização Microestrutural}

O valor obtido para energia de falha de empilhamento através do modelamento proposto por Dumay et al. [11] foi de $14,5 \mathrm{~mJ} / \mathrm{m}^{2}$ [22], indicando a ocorrência de transformação martensítica como mecanismo complementar de deformação plástica, i.e., além da maclação mecânica e escorregamento de discordâncias.

As figuras 2 e 3 ilustram micrografias obtidas no MEV para as amostras recozidas por 100, 300 e 1000 s, após laminação a frio com 45 e 90\% de redução. Na figura 3(a) a maior parte da microestrutura se encontra encruada. Após $300 \mathrm{~s}$ de recozimento a microestrutura se recristaliza, formando nanogrãos, Figura 3(b). Já na Figura 3(c) se observa com mais clareza as placas de martensita $\varepsilon$, regiões claras e em relevo, agulhas de $\alpha$, em zig-zag e também em relevo, ou formando triângulos equiláteros, sobre uma matriz de austenita. De acordo com Ding et al. [20], a martensita $\varepsilon$ nucleiase através das falhas de empilhamentos geradas por discordâncias parciais ou diretamente da sobreposição dessas falhas, as quais são criadas nas interseções entre planos ativos de escorregamento ou nos contornos de grão e maclas. Além disso, segundo Liang et al. [23], existe uma diferença de orientação cristalográfica em torno de $70^{\circ}$ entre as placas de martensita $\varepsilon$. Já a martensita $\alpha^{\prime}$ é normalmente formada nas interseções de duas placas de martensita $\varepsilon$, entretanto, outros planos de escorregamento podem atuar como sítios de nucleação para a sua formação [11,14,17]. A análise por difração de raios $X$ confirmou a presença das fases austenita, martensita $\varepsilon$ e $\alpha^{\prime}$ (Figura 4) nas amostras encruadas e recozidas por 100, 300 e 1000 s.

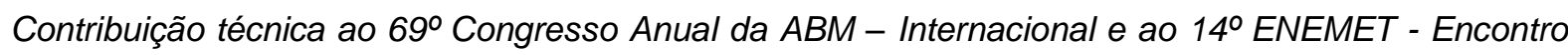
Nacional de Estudantes de Engenharia Metalúrgica, de Materiais e de Minas, 21 a 25 de julho de 2014, São Paulo, SP, Brasil. 


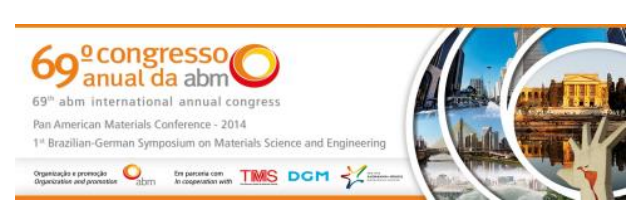

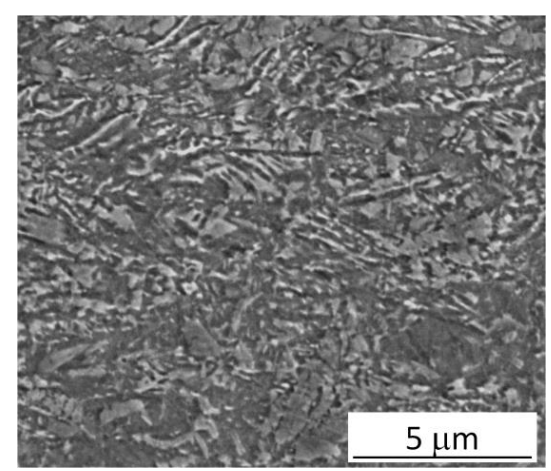

(a)

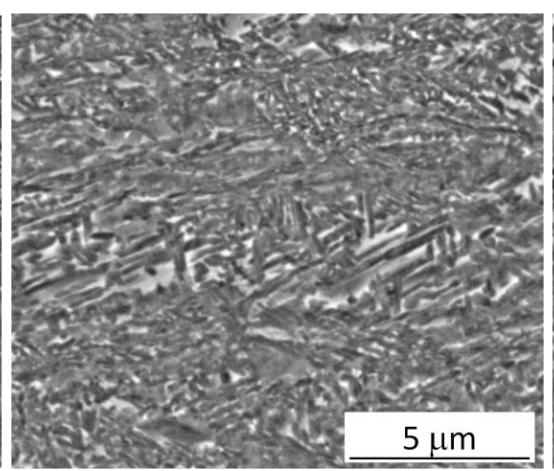

(b)

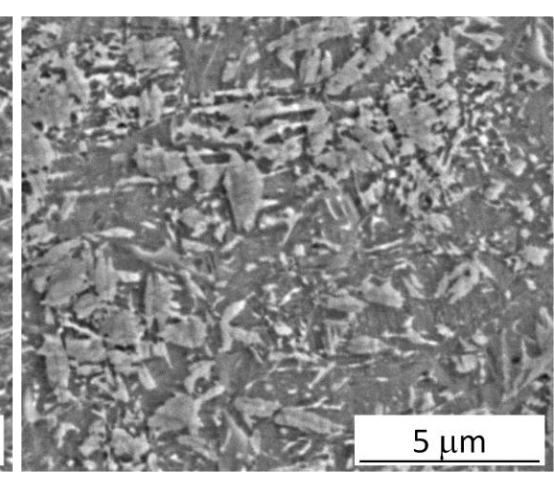

(c)

Figura 2. Microscopia eletrônica de varredura das amostras laminadas com $45 \%$ de redução e recozidas com tempos de (a) $100 \mathrm{~s}$, (b) $300 \mathrm{~s} \mathrm{e} \mathrm{(c)} 1000 \mathrm{~s}$. Ataque com reativo de Villela.

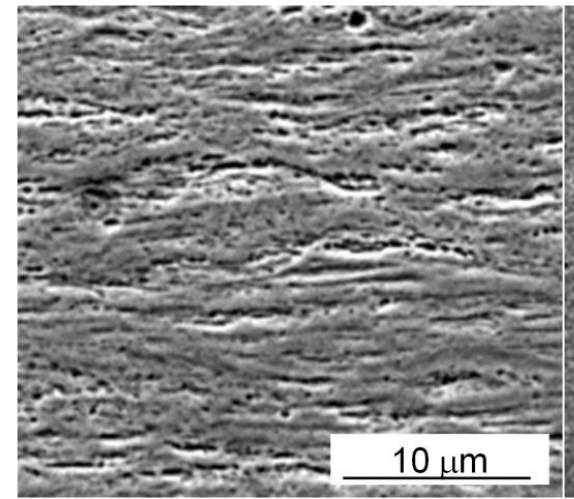

(a)

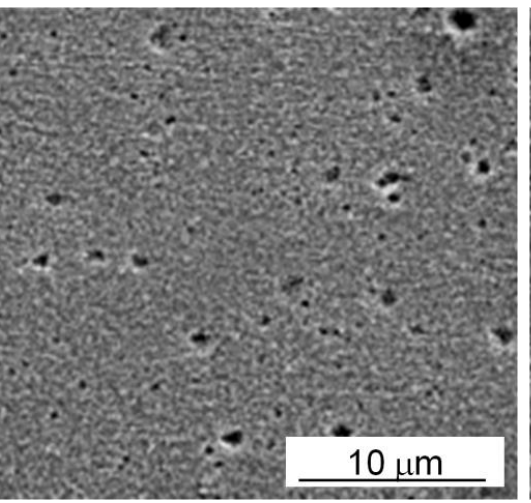

(b)

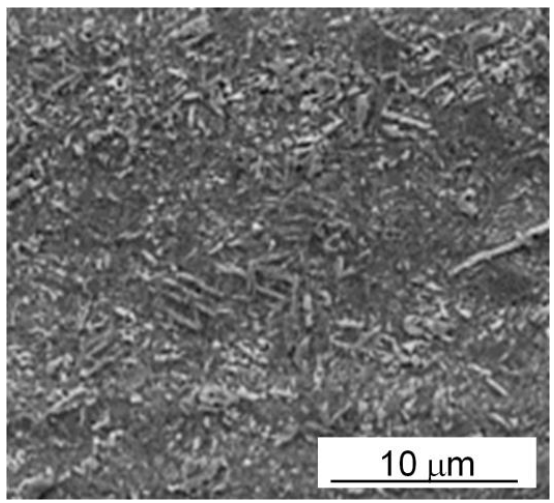

(c)

Figura 3. Microscopia eletrônica de varredura das amostras laminadas com $90 \%$ de redução e recozidas com tempos de (a) $100 \mathrm{~s}$, (b) $300 \mathrm{~s} \mathrm{e} \mathrm{(c)} 1000 \mathrm{~s}$. Ataque com reativo de Villela.

Os resultados da quantificação das fases austenita $(\gamma)$, martensita $\alpha^{\prime}$ e $\varepsilon$ em função do tempo de recozimento estão listados na Tabela 2. Um resultado marcante é transformação da austenita para martensita $\alpha^{\prime}$ após a deformação imposta na laminação a frio. No caso da redução de $90 \%$, praticamente toda a austenita existente após a laminação a quente [23] se transforma para martensita $\alpha^{\prime}$, Figura 4(b). Outro fator importante que foi considerado para a realização dos ensaios de tração é a presença de austenita na amostra recozida. Nesse caso, optou-se pela amostra recozida por $300 \mathrm{~s}$. Os resultados dos ensaios mecânicos serão relatados a seguir na seção própria. Na Figura 5 são ilustradas a microestrutura das amostras recozidas por 1000 s. As imagens na Figura 5 correspondem a figura de polo inversa (IPF) obtidas por EBSD. Nota-se claramente o reduzido tamanho de grão gerado no processo de deformação e recozimento. É importante observar que na Figura 5(b) a barra de escala micrométrica corresponde a $3 \mu \mathrm{m}$, ou seja, o aço produzido apresenta uma microestrutura nanométrica. Isto é importante na interpretação do comportamento mecânico do aço em estudo. Por sua vez, o tamanho do grão foi medido utilizando o software OIM 6.1, com imagens da Figura 5 e os resultados são apresentados na Figura 6. Observa-se que esse corresponde à cerca de $2 \mu \mathrm{m}$ para a redução de $45 \%$ e um valor entre em torno de 1,5 $\mu \mathrm{m}$ para redução de $90 \%$. Para o recozimento por $100 \mathrm{~s}$ ainda resta uma fração volumétrica de grãos não recristalizados (Figuras 2(a) e 3(a). 

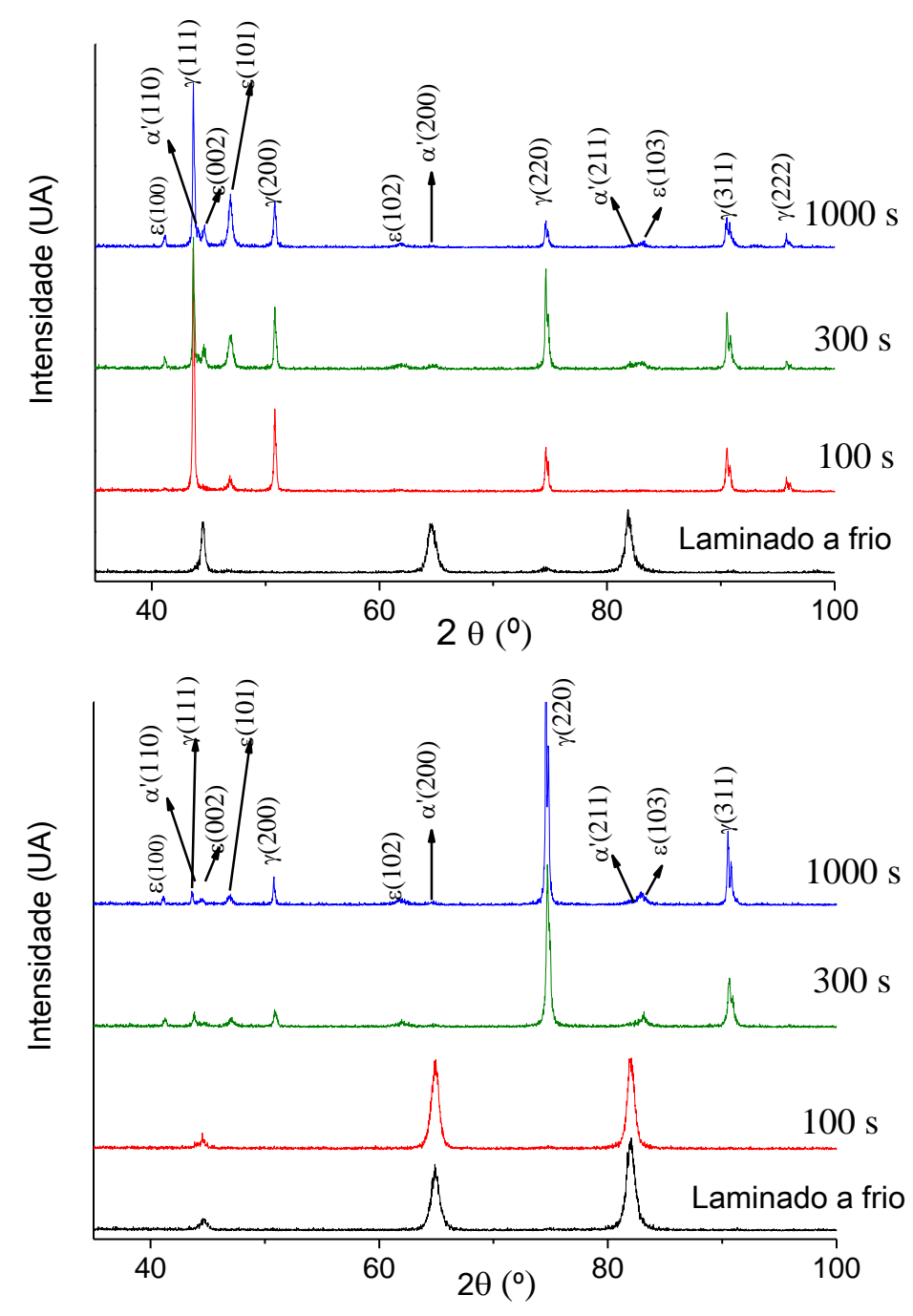

(a)

Figura 4 - Difratogramas obtidos para as amostras recozidas a $700^{\circ} \mathrm{C}$ por 100,300 e $1000 \mathrm{~s}$; (a) $45 \%$ e (b) $90 \%$ de redução.

Tabela 2. Fração volumétrica obtida a partir da difração de raios $X$ das amostras laminadas a frio com $45 \%$ e $90 \%$ e recozidas a $700^{\circ} \mathrm{C}$ durante 100,330 e $1000 \mathrm{~s}$

\begin{tabular}{|c|c|c|c|c|c|c|}
\hline \multirow{2}{*}{ Amostra } & \multicolumn{3}{|c|}{$\begin{array}{c}\text { Fração Volumétrica (\%) } \\
(\mathrm{LF}-45 \%)\end{array}$} & \multicolumn{3}{c|}{$\begin{array}{c}\text { Fração Volumétrica (\%) } \\
\text { (LF - 90\%) }\end{array}$} \\
\cline { 2 - 8 } & $\gamma$ & $\varepsilon$ & $\alpha^{\prime}$ & $\gamma$ & $\varepsilon$ & $\alpha^{\prime}$ \\
\hline Laminada a frio & 9,5 & 12,2 & 78,3 & 1,37 & - & 98,6 \\
$700^{\circ} \mathrm{C}-100 \mathrm{~s}$ & 71 & 23 & 6 & 1.7 & - & 98,3 \\
$700^{\circ} \mathrm{C}-300 \mathrm{~s}$ & 64 & 28 & 8 & 77,5 & 20,1 & 2,5 \\
$700^{\circ} \mathrm{C}-1000 \mathrm{~s}$ & 33 & 45 & 22 & 80,8 & 17,9 & 1,3 \\
\hline
\end{tabular}

\subsection{Análise da Textura}

A Figura 7 descreve, usando a função de distribuição de orientações (FDO), a textura da austenita observada em $\varphi 2=0^{\circ} \mathrm{e} \varphi 2=45^{\circ}$ para as amostras laminadas a frio com $45 \%$ e $90 \%$ de redução e recozidas a $700^{\circ} \mathrm{C}$ durante 100,300 e 1000 s. 


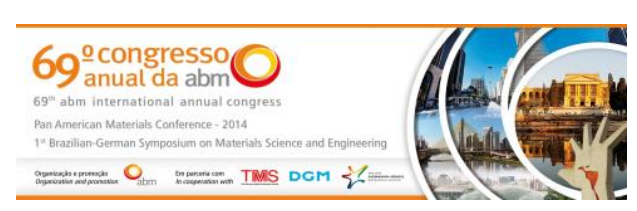

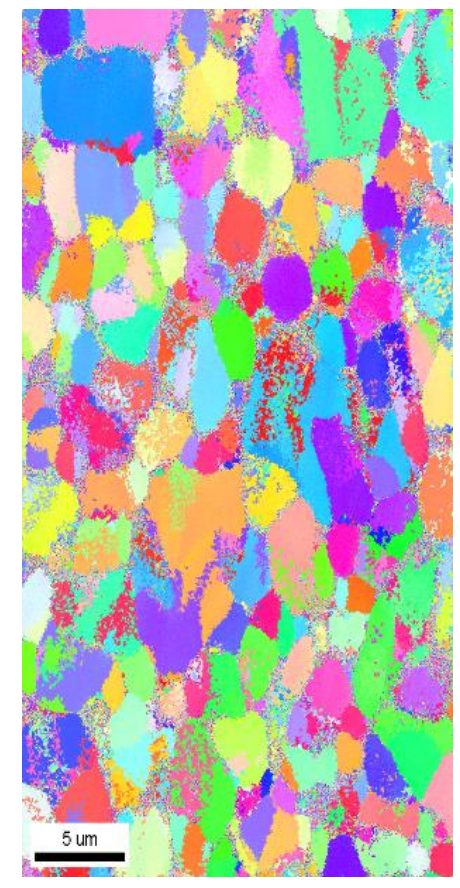

(a) $45 \%-700 \div \mathrm{C}-1000 \mathrm{~s}$

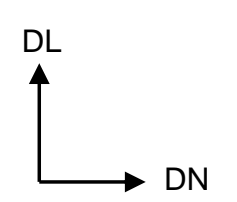

Austenite
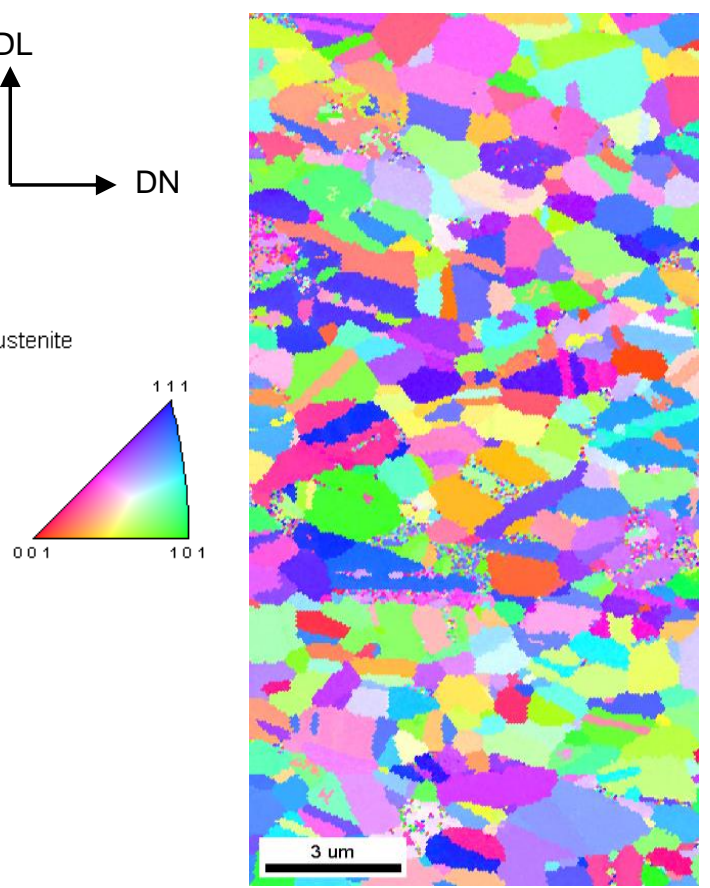

(b) $90 \%-700^{\circ} \mathrm{C}-1000 \mathrm{~s}$

Figura 5 - Imagens de EBSD-IPF,figura de polo inversa das amostras recozidas por $1000 \mathrm{~s}$. DLDireção de Laminação; DN - Direção Normal.
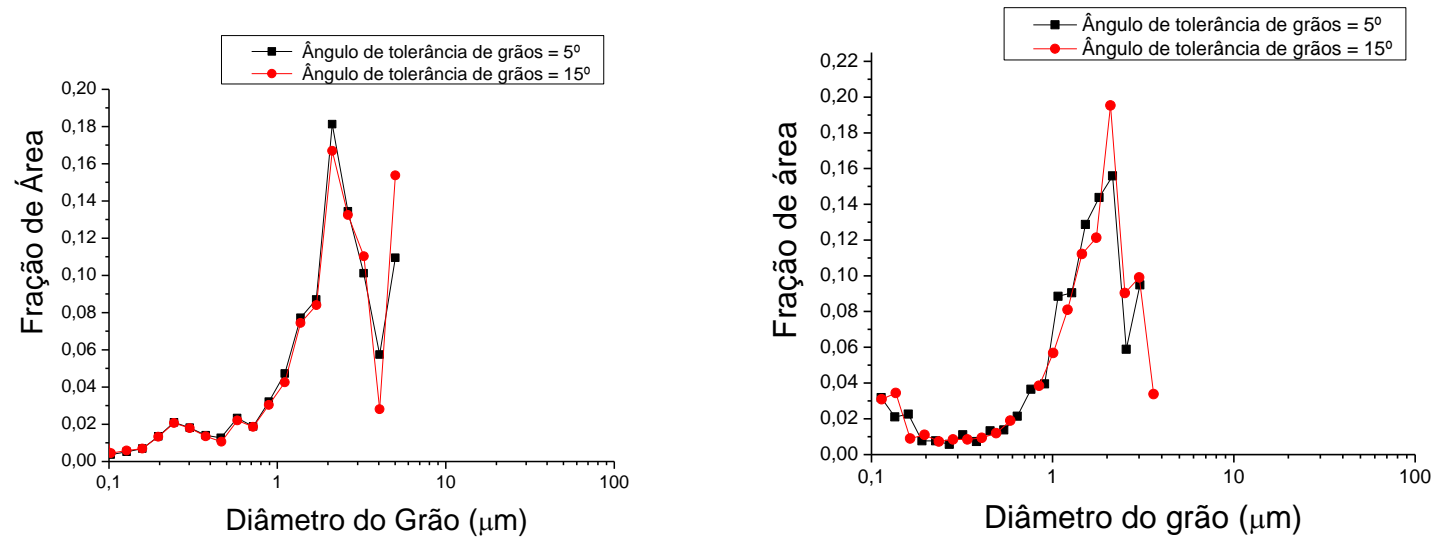

Figura 6. Tamanho médio do grão das amostras para o tempo de $1000 \mathrm{~s}$ de recozimento.

Para a amostra laminada a frio com $45 \%$ é possível observar que, depois de $100 \mathrm{~s}$ de recozimento, a textura não está bem definida, contudo, contém as componentes Latão, Cobre e traços de Goss. No entanto, quando o tempo de recozimento aumenta, nota-se que as componentes Cobre e Latão são incrementadas.

$\mathrm{Na}$ amostra laminada com $90 \%$, ambas as componentes, Cobre e Latão, já eram fortes mesmo no início do recozimento (100 s). A textura apresentando uma componente definida do tipo Cobre é característica de metais CFC após a recristalização. Esta é reforçada à medida que o tempo de recozimento é incrementado. Este comportamento sugere um processo de nucleação orientada [7,24]. Com o aumento do tempo de recozimento as componentes Cobre e Latão são reforçadas para ambas reduções na laminação, 45\% e 90\%. 

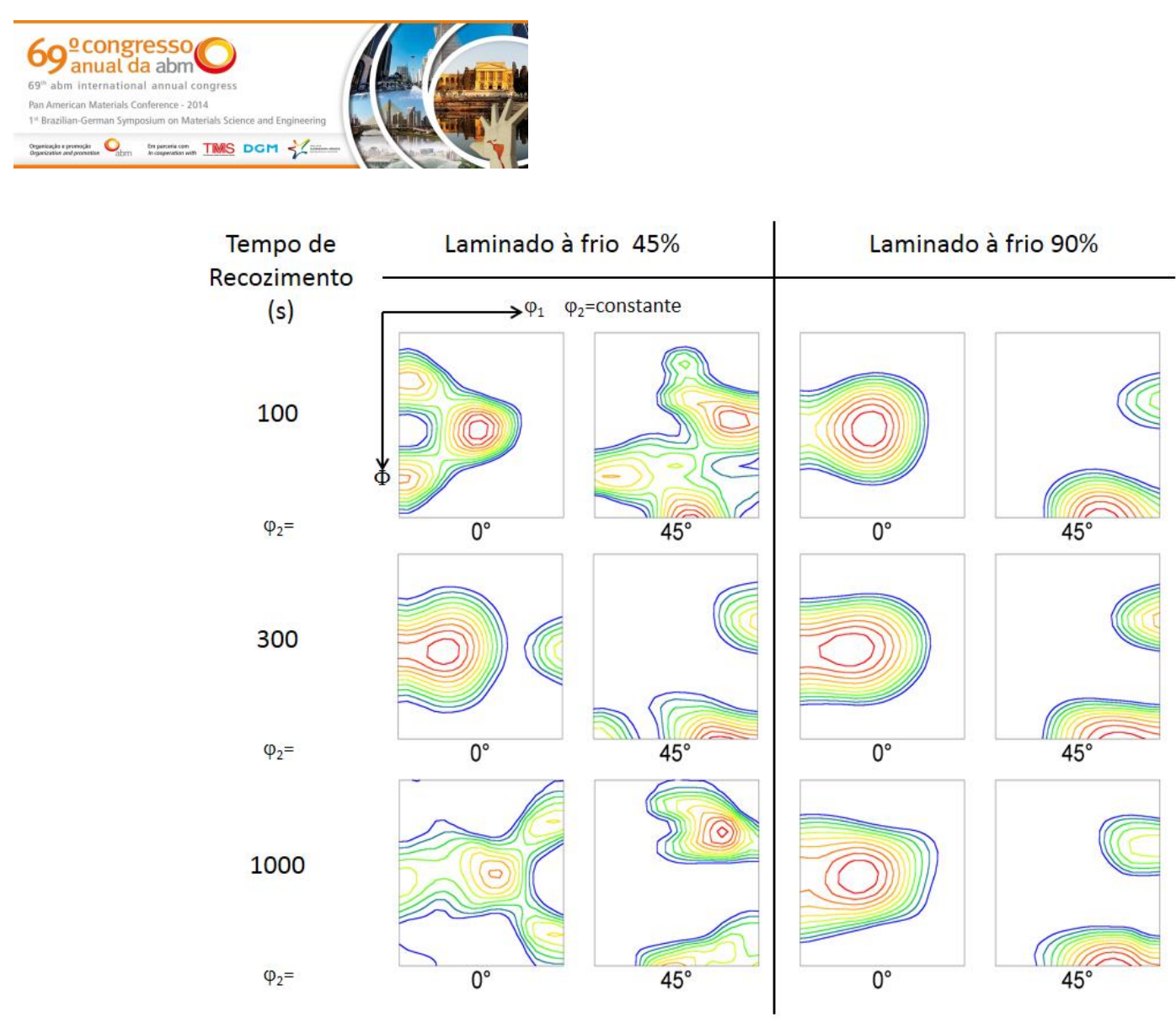

Figura 7. Textura da austenita observada em $\varphi 2=0^{\circ}$ e $\varphi 2=45^{\circ}$ para as amostras laminadas a frio com $45 \%$ e $90 \%$ de redução e, em seguida, recozidas a $700^{\circ} \mathrm{C}$ por 100,300 e $1000 \mathrm{~s}$.

\subsection{Propriedades Mecânicas}

A Figura 8 apresenta as medidas de microdureza Vickers da amostra encruada com $45 \%$ e das amostras recozidas no intervalo de 10 a $7200 \mathrm{~s}$ [23]. Os recozimentos levaram a um decréscimo acentuado de microdureza logo após os períodos iniciais do mesmo. Comportamento similar foi observado por Liu et al. [19] trabalhando com uma liga de $24 \% \mathrm{Mn}-0,02 \% \mathrm{C}$. O primeiro patamar indicado na Figura 8 refere-se à recristalização do aço $(250 \mathrm{HV})$, enquanto o segundo corresponde à etapa de crescimento de grão (225 HV). Durante o recozimento são eliminadas as discordâncias em excesso [23,24], maclas de deformação e reversão da martensita $\alpha^{\prime}$ para austenita [11]. A partir desses resultados, escolheu-se repetir as experiências adotando-se os tempos de encharque de 100,300 e 1000 s. A Figura 9 ilustra a evolução da microdureza Vickers para ambas condições de laminação a frio, $45 \%$ e $90 \%$. Como no experimento anterior (Figura 8) os valores de dureza convergem para $225 \mathrm{HV}$, independente da redução a frio prévia. De modo semelhante, tem-se a reversão da martensita $\alpha^{\prime}$ para austenita. No entanto, para tempos mais longos, 1000 s, ocorre a austenitização em maior intensidade (Figura 4, Tabela 2) no aço, seguida pela formação atérmica de martensita $\varepsilon$, que em sequência se transforma parcialmente para martensita $\alpha^{\prime}$. Culminando com a presença das três fases (martensitas $\varepsilon, \alpha^{\prime}$ e austenita) à temperatura ambiente (Figura 2-4). Tal fenômeno foi acompanhado por outros autores [20] em aços com teores de Mn mais altos, $22 \% \mathrm{Mn}$ e 0,024\%C, no trabalho de Fayen Lu et al. [21], ou no trabalho de Dafé et al. [22].

A Figura 10(a-c) ilustra as curvas tensão vs deformação de engenharia e as curvas tensão vs deformação verdadeiras, juntamente com resultados da taxa de encruamento, para amostras laminadas a frio a $45 \%$ e $90 \%$, e recozidas a $700^{\circ} \mathrm{C}$ por $300 \mathrm{~s}$. 

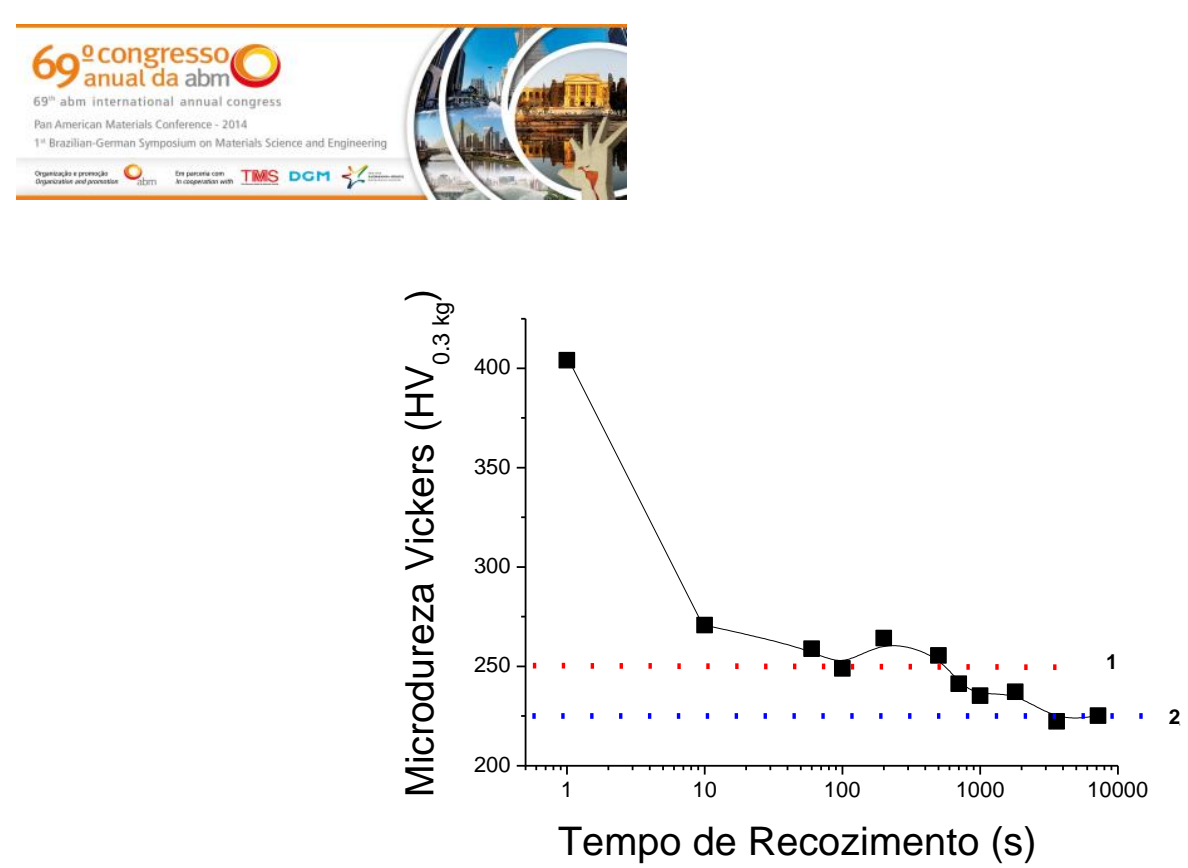

Figura 8 - Microdureza Vickers em função do tempo de recozimento das amostras laminadas com 45\% de redução e recozidas a $700^{\circ} \mathrm{C}$ em diversos tempos [24].

As Figuras 10(a,b) apresentam as curvas obtidas no teste de tração referentes ao material laminado a frio com 45 e $90 \%$ de redução e recozido por $300 \mathrm{~s}$ a $700^{\circ} \mathrm{C}$, respectivamente. Na Figura 10(c) são apresentadas as curvas de encruamento derivadas das respectivas curvas de tração. A interseção das curvas de tensão verdadeira e taxa de encruamento fornece o valor do expoente de encruamento, $n$, segundo o critério de Considère [25,26].

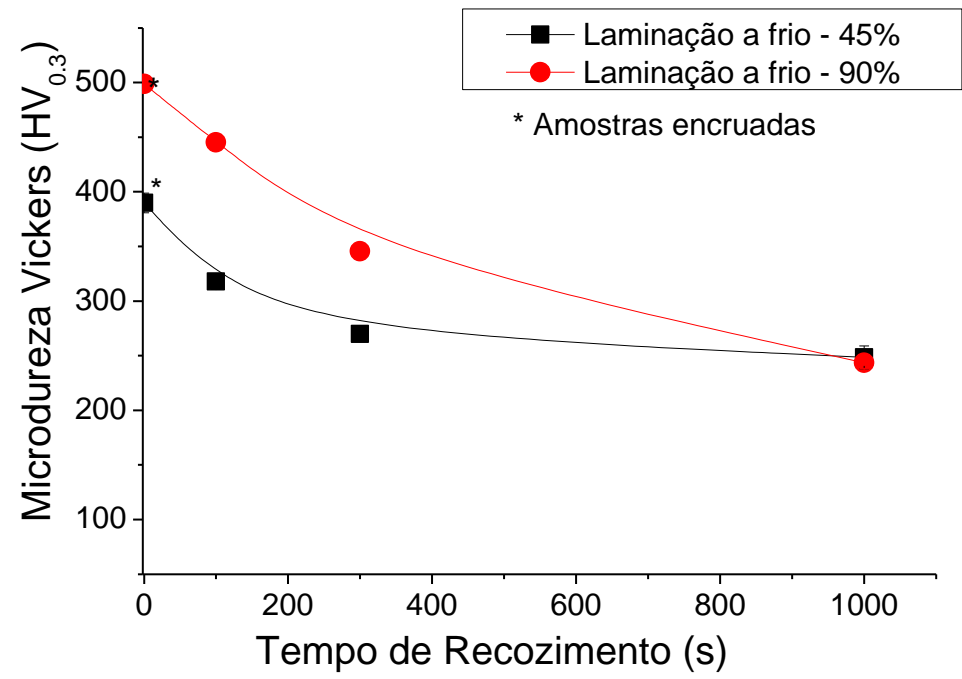

Figura 9. Microdureza Vickers em função do tempo de recozimento para as amostras laminadas a frio de $45 \%$ e $90 \%$ e tratados termicamente a $700^{\circ} \mathrm{C}$ durante 100,300 e $1000 \mathrm{~s}$.

Para a condição de laminado a frio $90 \%$ e recozido o aço apresentou valores de 750 $\mathrm{MPa}$ e $950 \mathrm{MPa}$ para os limites de escoamento e resistência, respectivamente, demonstrando a alta capacidade de encruamento do aço examinado, ou seja, um valor do expoente de encruamento, $n$, igual 0,33 . Esses valores podem ser considerados altos $[9,20,26]$. A interpretação dos dados da Figura 10 (c) revela que o encruamento do aço laminado a frio e recozido exibe pelo menos 3 estágios, à medida que a deformação plástica avança no teste de tração. O estágio número I corresponde ao escorregamento de discordâncias e a formação de maclas de deformação. O estágio número II corresponde a formação de martensita induzida por deformação, martensita $\varepsilon$

Contribuição técnica ao 69 Congresso Anual da ABM - Internacional e ao 14 ENEMET - Encontro Nacional de Estudantes de Engenharia Metalúrgica, de Materiais e de Minas, 21 a 25 de julho de 2014, São Paulo, SP, Brasil. 


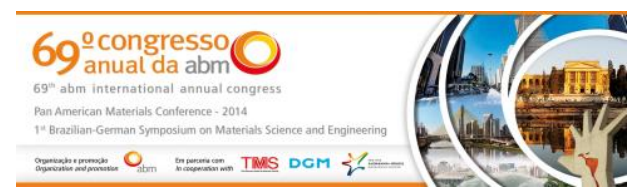

O limite de escoamento e resistência à tração, após laminação a frio com $90 \%$ e recozimento $700^{\circ} \mathrm{C}$ por $300 \mathrm{~s}$, alcançou valores de $750 \mathrm{MPa}$ e $950 \mathrm{MPa}$, com um alongamento total em torno de $50 \%$ e expoente de encruamento acima de 0,30 . A capacidade de encruamento do aço é aumentada devido aos efeitos TWIP/TRIP, resultante da transformação martensítica induzida por deformação. Foi comprovado por análise de textura que a reversão da austenita ocorre simultaneamente com recristalização da austenita, pois os componentes de Cobre e de Latão aparecem com forte intensidade nas amostras. Verificou-se que a formação de martensita $\varepsilon$ ocorre durante o processamento, e que se transforma imediatamente a martensita $\alpha^{\prime}$, que altera significativamente o comportamento mecânico do aço. A transformação induzida por deformação ocorre em duas etapas: $\gamma \rightarrow \varepsilon \rightarrow \alpha$ ' e a martensita $\alpha$ ' tende a ser a fase principal com o aumento da deformação a frio. Verificou-se que a microestrutura gerada após a reversão para austenita é mais refinada para as amostras que foram inicialmente submetidas a uma maior redução a frio, devido a uma nucleação mais intensa. Na etapa de resfriamento, após o recozimento, ocorrem também a formação atérmica de martensita $\varepsilon$, que se transforma parcialmente em $\alpha^{\prime}$.

\section{Agradecimentos}

Os autores agradecem à FAPEMIG, processo número PPM-V - 00308-13, ao CNPq, processo número 303148/2010-1, pelo apoio financeiro à execução desta pesquisa e concessão de bolsas de pesquisa aos autores, bem como a CAPES pela bolsa de pós-doutorado concedida a D.M.P.E.

\section{REFERÊNCIAS}

1 Kim Yg, Kim Tw, Han Jk, R.W. Chang Rw. Development of new austenitic Fe-Mn-Al-C steels for automotive applications. Key Engineering Materials, 1993; 84-85: 461.

2 Grassel O, Frommeyer G, Derder C, Hofmann H. Phase Transformation and Mechanical Properties of Fe-Mn-Si-Al TRIP-steels. Journal of Phyisique IV, 1997; C5: 383-388.

3 Frommeyer G, Brüx U, Neumann P. Supra-Ductile and High-Strength ManganeseTRIP/TWIP Steels for High Energy Absorption Purposes. ISIJ International, 2003; 43(3): 438-446.

4 Li DZ, Wei YH, Xu BS, Hou LF, Han PD. Development in fundamental research on TWIP steel used in automobile industry. Ironmaking and Steelmaking, 2011; 38(7): 540-545.

5 Cooman BC, Kwon O, Chin K.-G. State-of-the-knowledge on TWIP steel. Materials Science and Technology, 2012; 28: 513-527.

6 Chen L, Zhao Y, Qin X. Some Aspects of High Manganese Twinning-Induced Plasticity (TWIP) Steel, A Review. Acta Metallurgica Sinica (English Letters), 2013; 26(1): 1-15.

7 Bouaziz O, Allain S, Scott CP, Cugy P, Barbier D. High manganese austenitic twinning induced plasticity steels: A review of the microstructure properties relationships. Current Opinion in Solid State and Materials Science, 2011; 15: 141-168.

8 Lu Y, Molodov DA, Gottstein G. Recrystallization kinetics and microstructure evolution during annealing of a cold-rolled Fe-Mn-C alloy. Acta Materialia, 2011; 59: 3229-3243.

9 Vercammen S, Blanpain B, Cooman BC, Wollants P. Cold rolling behavior of an austenitic Fe-30Mn-3Al-3Si TWIP-steel: the importance of deformation twinning. Acta Materialia, 2004; 52: 2005-2012.

10 Jin JE, Lee YK. Strain hardening of a Fe-18Mn-0.6C-1.5AI TWIP steel. Materials Science and Engineering A, 2009; 527: 157-161.

11 Dumay A, Chateau JP, Allain S, Migot S, Bouaziz O. Influence of addition elements on the stacking-fault energy and mechanical properties of an austenitic Fe-Mn-C steel. Materials Science and Engineering A, 2008; 483-484: 184-187.

Contribuição técnica ao 69ํㅡㄹ Congresso Anual da ABM - Internacional e ao 14ํㅡㄹ ENEMET - Encontro Nacional de Estudantes de Engenharia Metalúrgica, de Materiais e de Minas, 21 a 25 de julho de 2014, São Paulo, SP, Brasil. 
